Submission ID: 43859

\title{
Forecast of Fracture and Cavernous Reservoirs of the North-Barents Shelf
} by Scattered Waves

L.F. Zhegalina* (Immanuel Kant Baltic Federal University), G.N. Erokhin (Immanuel Kant Baltic Federal University), E.V. Anokhina (Immanuel Kant Baltic Federal University), M.N. Nazarova (Immanuel Kant Baltic Federal University)

\section{SUMMARY}

The results of a complex interpretation of the reflected and scattered wave fields are presented to refine the fault-block model and fracture and cavernous reservoirs forecasting of both tectonic and lithogenetic origin. The forecast is based on the original pre-stack migration method - Common Scattering Point Dip (CSPD). 
Прогноз трещинно-кавернозных резервуаров шельфа Баренцева моря на основе рассеянных волн

Г.Н. Ерохин, Л.Ф. Жегалина*, М.Н. Назарова, Е.В. Анохина (НИИ прикладной информатики и математической геофизики Балтийского федерального университета имени И. Канта, г. Калининград)

\section{Введение}

При слабой изученности шельфа Баренцева моря бурением, актуальным становится применение нетрадиционных методов обработки сейсмических материалов. Задачу повышения достоверности прогноза резервуаров с трещинным типом коллектора выполняет используемый авторами метод Common Scattering Point Dip (CSPD) на рассеянных волнах. С целью прогнозирования трещинно-кавернозных коллекторов проведена специализированная обработка полевых сейсмограмм 2D на Трубятченской площади Предновоземельской структурной области.

Известно, что основной объем резервуаров с трещинно-поровым и трещинно-кавернозным типом коллектора формируется в зонах разрывных нарушений и в областях повышенных напряжений, создаваемых на сводах и склонах положительных структур. Безамплитудные разломы не всегда возможно картировать на стандартных временных разрезах отраженных волн. Но эти разломы создают зоны развития трещиноватости, которые в поле рассеянных (дифрагированных) волн отражаются повышенными значениями их амплитуд.

\section{Методика обработки и комплексной интерпретации данных по методу CSPD}

Common Scattering Point Dip (CSPD) - метод престековой миграции до суммирования, позволяющий выделять рассеянные волны из полного волнового поля. Он реализует строгое решение обратной задачи разделения полного волнового поля на отраженную и рассеянную компоненты. Математически корректное разделение волн позволяет визуализировать невидимые при стандартной обработке сейсмических данных рассеивающие элементы. Метод CSPD позволяет получать временные разрезы и кубы дифракторов, содержащие изображение только рассеивающих элементов среды (CSPD-дифракторы) и временные кубы (разрезы) рефлекторов без этих рассеивающих элементов (CSPD-рефлекторы). CSPD-дифракторы содержат уникальную информацию о трещиноватых зонах, которая при традиционной обработке сейсмических данных полностью теряется на фоне гораздо более интенсивных отражающих элементов. Кроме этого, качество CSPD-рефлекторов обычно выше, чем при традиционной обработке. Повышение качества происходит благодаря вычитанию рассеянных волн, являющихся для рефлекторов волнами-помехами [1].

Таким образом, если разрез отраженных волн (рефлекторов) использовался в основном для корреляции целевых горизонтов и построения разломно-блоковой модели, то разрез рассеянных волн (дифракторов) использовался для прогноза зон развития трещиннокавернозных коллекторов и уточнения модели разломной тектоники.

\section{Примеры прогноза коллекторов трещинного типа на основе рассеянных волн}

Как известно, на Трубятчинской площади наиболее высокими перспективами нефтегазоносности обладает юрско-неокомский ПНГК, в котором ожидается присутствие высокоемких коллекторов и надежных флюидоупоров. В тоже время, значительной перспективностью обладают и отложения триасового ПНГК. Этот нефтегазоперспективный комплекс значительно нарушен разломами, что предполагает формирование трещинного типа коллектора в отложениях нижнего и среднего триаса. Региональной покрышкой для резервуаров триасового ПНГК служат глинистые отложения верхнего триаса. 


\section{EAGE}

Анализ временных полей рассеянных волн интервала отложений триаса показывает, что в этой части осадочного чехла вероятно наличие резервуаров с трещинным (трещинно-поровым) типом коллектора. Одни приурочены к узким зонам, связанным с разрывными нарушениями кайнозойского этапа, и имеют характерную столбообразную форму. Резервуар такого типа выделен на поднятии Гидрографов (рис. 1).

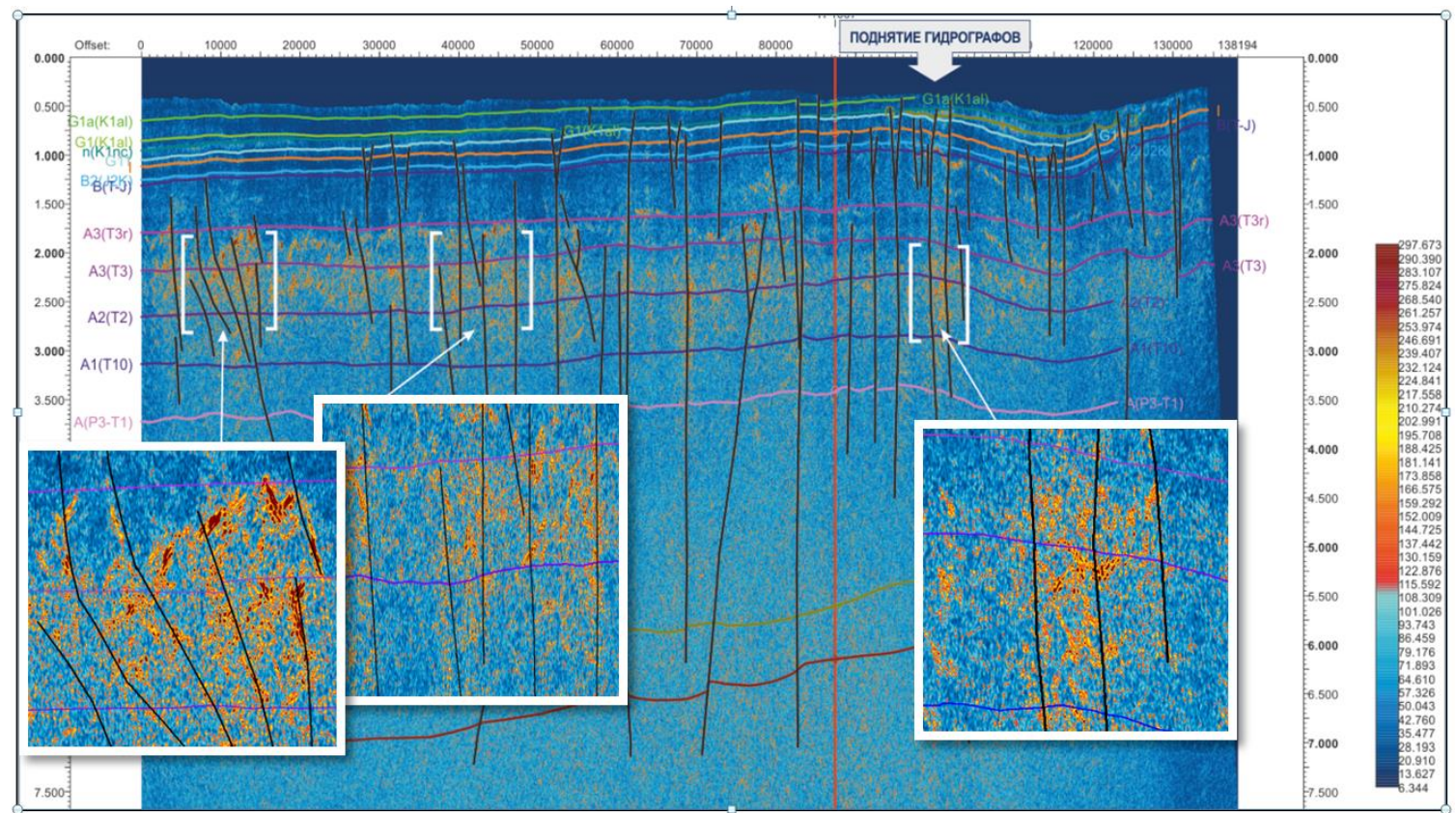

Рисунок 1 Резервуары в отложениях нижнего и среднего триаса с трещинным типом коллектора по профилю 1.

Другой тип резервуаров с трещинным типом коллектора, образованный в зонах повышенных напряжений на сводах и присводовых частях положительных структур, выявлен в пределах Сальмской структуры (рис. 2). Резервуар охватывает отложения нижнего и среднего триаса, а флюидоупором являются глинистые породы верхнего триаса.

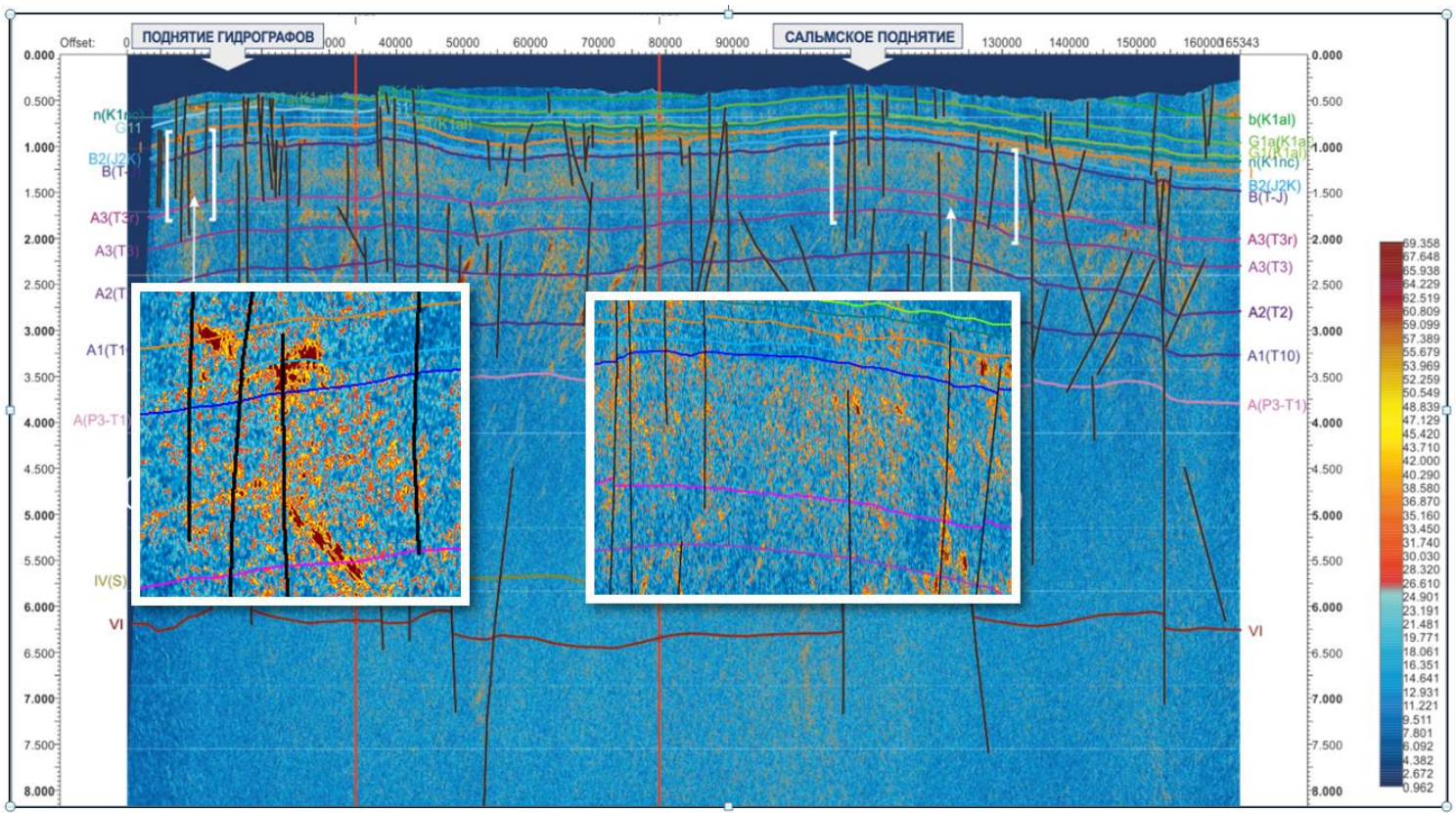

Рисунок 2 Прогнозируемые резервуары в отложениях верхнего триаса и юры с трещинным типом коллектора (временной разрез по профилю 2). 


\section{EAGE}

Наряду с тектоническими существуют и другие виды трещин, такие как литогенетические [2]. Из-за хаотического распределения литогенетических трещин по породе, зоны их развития практически не отражаются в поле отражённых волн, а чётко фиксируются в поле рассеянных волн и метод CSPD является эффективным для картирования такого типом трещиноватости. Наличие таких зон в верхней части разреза зачастую являются зонами сильного поглощения при бурении скважин а их картирование может предотвратить связанные с ними осложнения. Примером могут служить зоны трещиноватости в отложениях придонной части осадочного чехла на профиле 3 (рис. 3).

Резервуар с трещинным типом коллектора закартирован в пределах ступени Конрада (рис. 3). Профиль 3 пересекает ступень Конрада, прогиб Святой Анны, перемычку Разломную и прогиб Фобос западный. В отложениях юры, мела и верхнего триаса в западной части прогиба Фобос Западный проявляется зона с высокими значениями амплитуд, что указывает на коллектор трещинного типа. Однако отсутствие надежного флюидоупора не позволяет прогнозировать здесь наличие резервуара. Он охватывает отложения неокома, а флюидоупором служат глинистые отложения альба.

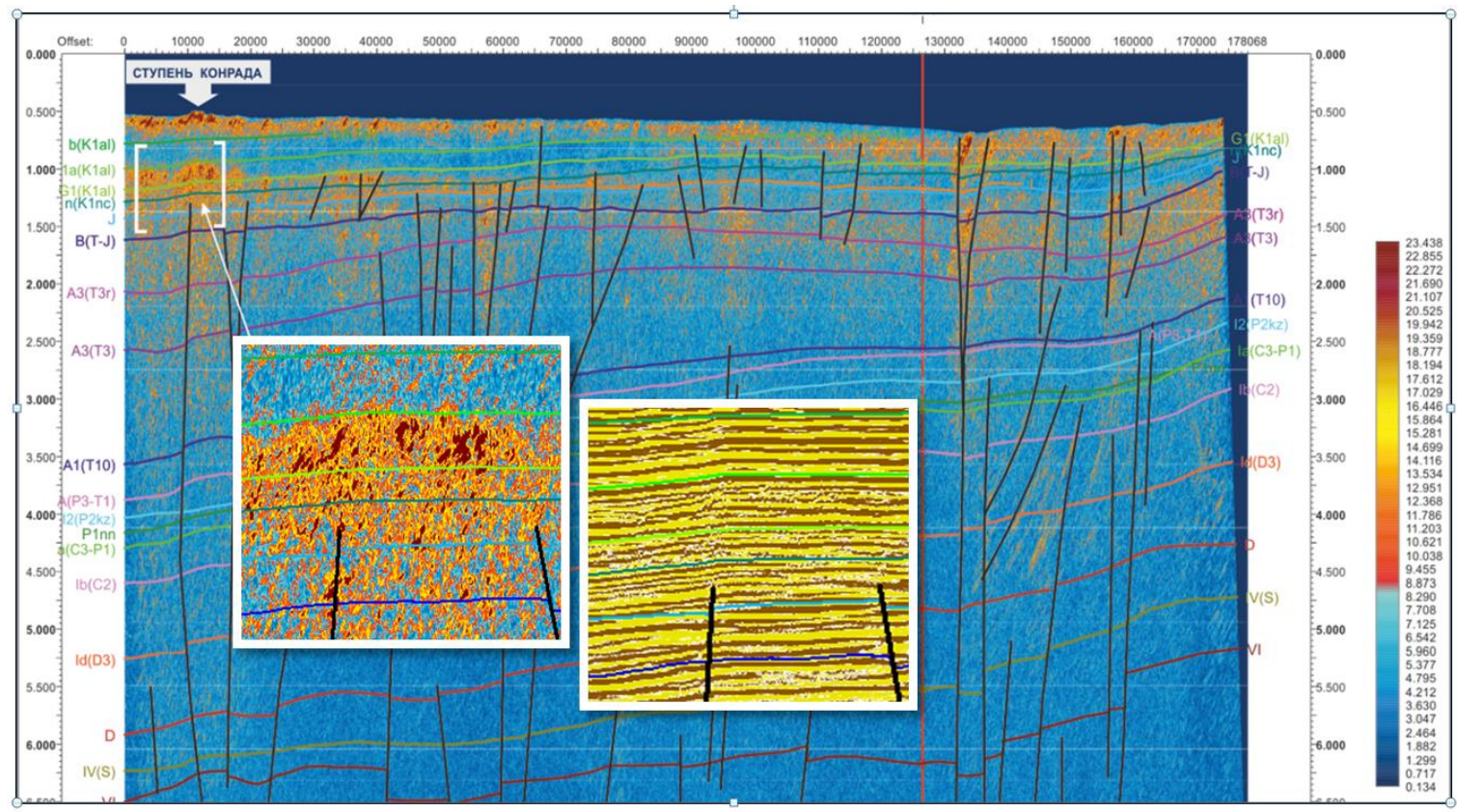

Рисунок 3 Прогнозируемые резервуары в отложениях неокома с трещинным типом коллектора по профилю 3 в поле рассеянных и отраженных волн (справа).

В пределах поднятия мыса Желаний прогнозируется несколько резервуаров с коллекторами трещинного типа. На профиле 4, который пересекает поднятие по короткой оси, фиксируется резервуар с коллекторами трещинного типа хорошего качества (рис. 4а). На профиле 5, пересекающем поднятие по длинной оси, фиксируется две зоны с высоко ёмкими коллекторами (рис. 4б). 


\section{EAGE}
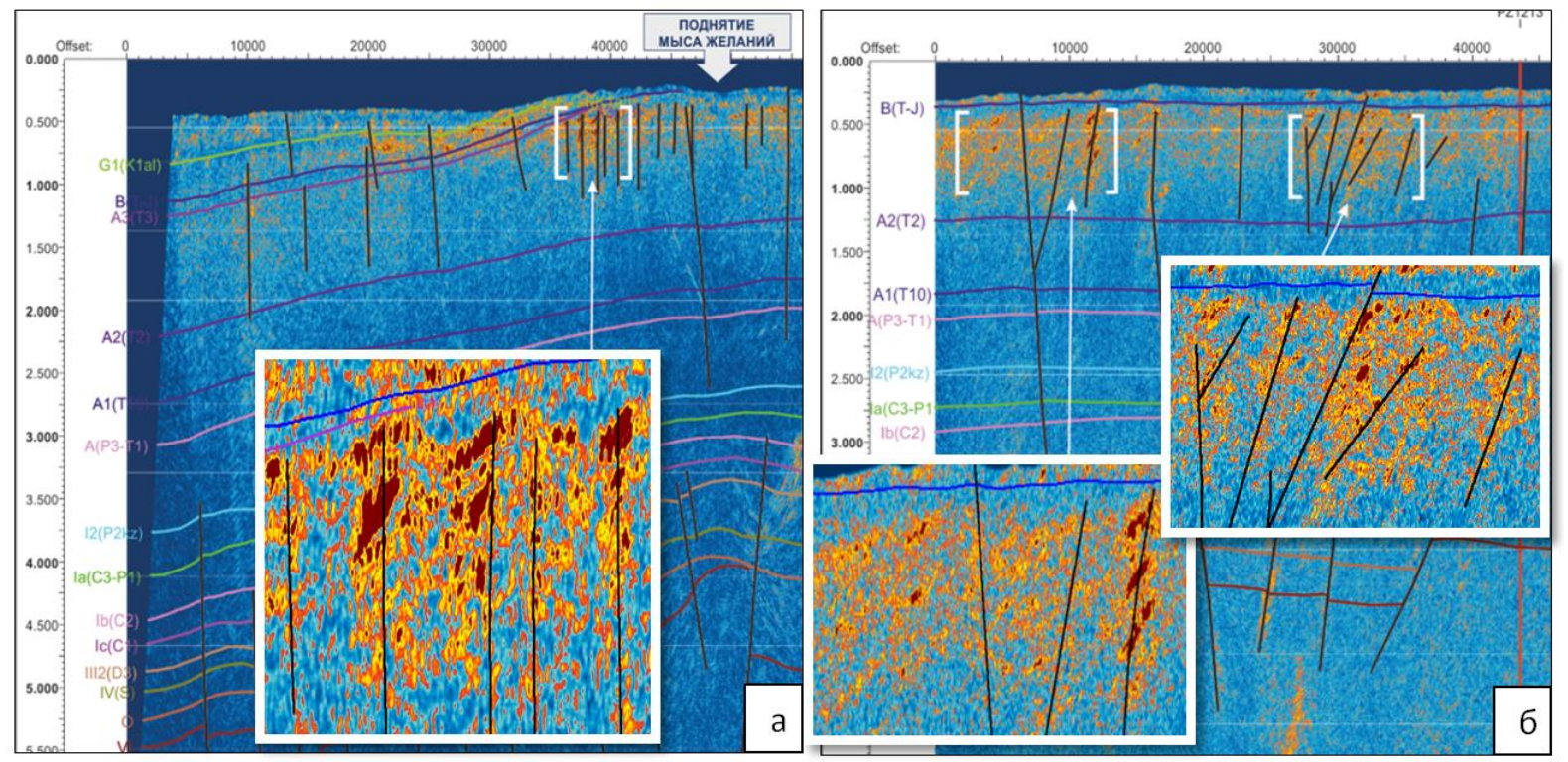

Рисунок 4 Резервуары в отложениях верхнего триаса с трещинным типом коллектора по профилям 4 (а) и 5 (б) в поле рассеянных волн.

\section{Выводы}

Исследования, выполненные в Северо-Баренцевском регионе показали, что наиболее перспективными для поиска являются положительные структурные формы региона, в пределах которых на профилях выявлены резервуары с трещинным коллектором различных типов и размеров. В пределах Орловского мегавала на Сальмском поднятии выявлены ловушки в отложениях триаса, юры и мела, на Трубятченском мегавалу в пределах поднятия Гидрографов выявлены ловушки в отложениях триаса, юры и мела. В пределах мыса Желания ловушки выявлены в отложениях триаса. В пределах ступени Конрада ловушки охватывают отложения юры и мела.

Использование поля рассеянных волн при прогнозе резервуаров с трещинным типом коллектора, особенно эффективно в сложно построенных геологических средах [3]. Комплексная интерпретация временных разрезов рефлекторов и дифракторов позволила создать детальную и более достоверную разломно-блоковую модель геологической среды и выполнить прогноз с целью поиска резервуаров с трещинным типом коллектора как тектонического, так и литогенетического происхождения.

\section{Библиография}

1. Анохина Е.В., Киричек А.В., Ерохин Г.Н., Кремлев А.Н. Карбонатные резервуары в поле рассеянных волн // Труды 5-ой международной научно-практической конференции «ГЕОКРЫМ_2015. Проблемы нефтегазовой геологии и геофизики», Крым, г. Алушта. 18 22 мая 2015

2. Чернышов С.Н. Трещины горных пород. М.: Наука, 1983. 240с.

3. Стариков Л.Е., Киричек А.В., Кремлев А.Н., Ерохин Г.Н., Жегалина Л.Ф. Методика геологической интерпретации поля рассеянных волн, полученных по методу Common Scattering Point // Тезисы третьей международной научно-практической конференции Калининград - 2013. 2013. С. 252-255. 


\section{References}

1. Anokhina E.V., Kirichek A.V., Erokhin G.N., Kremlev A.N. The carbonate reservoirs in the field of the scattered waves. // Paper presented at the fifth international scientific-practical conference "GEOKRYM_2015. Problems of Petroleum Geology and Geophysics", Alushta, 18-22 May, 2015

2. Chernyshov S.N. Cracks of rocks. M.: Nauka, 1983. 240.

3. Starikov L.E., Kirichek A.V., Kremlev A.N., Erokhin G.N., Zhegalina L.F., 2013. Methods of geological interpretation of the field scattered waves obtained by the Common Scattering Point method. Paper presented at the Third International scientific-practical conference "Problems and achievements of modern petroleum geology", Kaliningrad, May 27-31. 2013: 252-255. 